\title{
Treinar cirurgiões: hoje como sempre?
}

\section{Surgions train: always like today?}

LISIEUX EYER DE JESUS, TCBC-RJ1

\section{R E S U M O}

\begin{abstract}
Este artigo pretende discutir a metodologia de treinamento dos novos cirurgiões, considerando a realidade do momento atual e propondo uma reflexão orientada baseada em evidências a respeito das expectativas dos cirurgiões jovens e da realidade do mercado de trabalho em cirurgia. As descobertas cientificas e tecnológicas, o grande volume de informação imposto rotineiramente e as expectativas de administração logistica e de custos modificaram de forma radical a atividade do cirurgião com relação aos cirurgiões formados nas concepções clássicas. Há um reposicionamento da autoridade do médico frente ao paciente e à sociedade. A cultura contemporânea leva os jovens a ter expectativas próprias quanto à própria qualidade de vida e perspectivas profissionais. Tornou-se necessário modificar os padrões de treinamento dos cirurgiões para que se adeqüem à necessidade de aprendizado contínuo e adaptação a novos instrumentos tecnológicos e para que estejam aptos a uma interação social adequada à expectativa atual quanto à relação médico-paciente e entre profissionais de saúde. Estas adaptações estruturais são fundamentais para manter $\mathrm{o}$ interesse dos profissionais jovens em cirurgia.
\end{abstract}

Descritores: Educação médica. Cirurgia/educação. Prática profissional.

$H^{\circ}$ je a informação em medicina é extremamente fluida: a tecnologia modifica condutas clássicas e derruba dogmas centenários. Há bem pouco tempo se provou que operar casos de apendicite de forma semi-eletiva (evitando as cirurgias das madrugadas) ${ }^{1}$ ligar o apêndice sem invaginá$10^{2}$ e tratar casos selecionados de forma não operatória ${ }^{3}$ está perfeitamente bem, só para dar um exemplo corriqueiro que perturba gravemente as mentes mais clássicas. E, ferindo ainda além os dogmas clássicos, a argumentação para defender estas condutas é baseada principalmente na conveniência logística das cirurgias diurnas para as administrações de pessoal hospitalar e dos centros cirúrgicos e em preceitos de economia de custos.

Novas informações são disponibilizadas a cada dia aos borbotões, e dois grandes problemas se impõem ao profissional: estar a par do progresso e selecionar entre tantos dados os que são reais, os que são confiáveis e os que são úteis, considerando inclusive que estes três aspectos podem perfeitamente não ser coincidentes ${ }^{4}$. Deduzir quando algo que é estatisticamente significativo é clinicamente relevante, perceber quando uma alternativa é excelente para uma população de países desenvolvidos mas é inadequada para países em desenvolvimento, reconhecer que metanálises simplesmente derivam (e multiplicam) os erros das amostras originais. Todas habilidades francamente dependentes da formação sólida de um raciocínio científico e de uma autonomia intelectual independente de relações de autoridade e poder. Sem capacidade de julgamento crítico o dogmatismo clássico tende a ser substituído por no- vos defeitos: as idéias de que qualquer novidade, qualquer tecnologia e toda forma de globalização são benéficas intrinsecamente.

De fato, todo ensino é necessariamente revolucionário. Qualquer aprendizado implica análise crítica: aprender de fato induz o aprendiz a atribuir significados e perceber implicações no conteúdo aprendido. Aprender significa assimilar novos conteúdos que interagem com a bagagem pessoal prévia do indivíduo e a modificam, criando uma nova bagagem intelectual, modificada com relação à anterior. Aprender significa remodelar a própria visão de mundo $^{5}$. Um efeito direto é criticar o estabelecido previamente, duvidar por definição, rejeitar uma estabilidade definitiva das verdades e representações. Representando um ato óbvio de coragem, aprender (e ensinar) significa desistir de resistir à mudança e abrir mão das ilusões de certezas e estabilidades absolutas. Considerado desta forma, ensinar é extremamente diferente de treinar/adestrar.

Em meio a tudo isto, como treinar cirurgiões? Ou, questionando de outra forma, treinar ou ensinar cirurgiões?

Definitivamente a proposta de treinamento exaustivo para adestrar mecânica e moralmente o indivíduo que se propõe a ser cirurgião não é mais suficiente, embora evidentemente persista fundamental o desenvolvimento de habilidades motoras e a formação disciplinar dos cirurgiões. A ideia de que a exposição pura e simples aos problemas e suas soluções adequará o profissional para exercer seu trabalho plenamente não é mais realista. O

1. Cirurgiã Pediátrica do Hospital Universitário Antonio Pedro, Universidade Federal Fluminense, Rio de Janeiro, Brasil e Hospital dos Servidores do Estado, Rio de Janeiro, Brasil - Researck Fellow Hospital for Sick Children, Universidade de Toronto - TCBC-RJ - T-CIPE. 
aprendizado pela repetição, pelo exemplo e pela intensidade não basta. O modelo do treinamento para prover prática, resiliência e disciplina (física e moral) pela intensidade de exposição, que é a base clássica da residência Halstediana ${ }^{6}$, precisa progredir, inclusive considerando as variações culturais que cercam o profissional enquanto pessoa e membro da comunidade, e impõem que aspectos morais e culturais de cada sociedade possam flexibilizar o exercício profissional.

O modelo de formação do cirurgião que usamos no Brasil foi diretamente importado a partir da sociedade americana, através das concepções de Flexner e Halsted (a partir das concepções da educação de cirurgiões na escola alemã, capitaneada por Billroth, onde se deu o treinamento do próprio William Halsted, em finais do século XIX), contendo as concepções de comportamento que orientam aquela sociedade e incluem a definição de sucesso apenas enquanto superação ilimitada, moralidade enquanto respeito específico e direcional à individualidade e uma identificação praticamente imediata entre insucesso, culpa e castigo. Firor cita as características cardinais do modelo Halstediano de treinamento em cirurgia: "contato íntimo entre residente e professor, competição árdua, tenacidade infinita, responsabilidade pela totalidade do tratamento dos pacientes... e participação em pesquisa"7. O destaque na alta competitividade e autoridade era tamanho que em uma visita a Boston a fim de avaliar o modelo de residência médica do serviço de Halsted, profissionais de Nova York retornaram assustados pelo comportamento autoritário do residente (à época, Harvey Cushing), e rejeitaram o modelo de formação proposto, que só foi implantado em Nova York após mais de 10 anos $^{6}$. A centralização na figura do preceptor (modelo individual aluno-preceptor) do modelo Halstediano eventualmente vem sendo substituída por modelagens baseadas em casos (centrada nas necessidades de exposição do aluno, que conviverá com os preceptores necessários para sua exposição a um " $n$ " clínico), que centraliza a formação no residente ou um modelo de "encaixe" do residente na equipe de saúde, derivado em geral das necessidades logísticas do serviço (centrado na instituição), sem que se tenha aberto mão das demais características do treinamento.

Será que esta modelagem se aplica corretamente à cultura contemporânea e latina em que estamos inseridos, que privilegia as relações de grupo, a relativa informalidade e o sucesso como integração dos vários aspectos de qualidade de vida individual? Ou, alternativamente, o enquadramento dos treinandos em cirurgia nesta escola de treinamento significa sofrimento desnecessário e desproporcional, inadequação e rejeição à especialidade? O estereótipo do cirurgião é intrínseco à personalidade dos cirurgiões ou ao modelo reconhecido de cirurgião, treinado desta forma? O treinando que se torna um profissional que repete este perfil se sente adequado ou é um candidato clássico à síndrome de burn-out?

O número de estudantes de medicina interessados numa carreira cirúrgica cai progressivamente em todo o mundo, desde a década de 90 . Nos EUA cerca de $10 \%$ das vagas de formação em cirurgia têm estado ociosas e no Brasil, embora a competitividade de vagas para treinamento básico em cirurgia geral persista elevada, raros pósgraduandos persistem na área da cirurgia geral: a maioria progride para especialização em áreas consideradas relativamente confortáveis para o exercício profissional, em especial cirurgia plástica e urologia ${ }^{8}$. Os principais argumentos para isto estão ligados direta ou indiretamente à busca de qualidade de vida pelos adultos jovens, em franca oposição com o longo tempo de treinamento, carga horária excessiva, entrada tardia no mercado de trabalho, responsabilização e culpabilidade absoluta e pessoal em caso de insucesso (pelos pares, pelos pacientes e pelo sistema legal vigente), tudo isso reforçado pelo reconhecimento da altíssima frequência de problemas de saúde (inclusive alcoolismo e síndrome da exaustão profissional) em cirurgiões de meia idade (o próprio Halsted foi viciado em cocaína e morreu vítima permanente do vício em opióides) ${ }^{6}$. Estes problemas são mais agudos para profissionais do sexo feminino (maioria dos estudantes de medicina neste momento): a formação se dá justamente na idade reprodutiva e as mulheres convivem rotineiramente com uma jornada de trabalho que extrapola largamente a do trabalho formal9,10. O paradigma moderno de atuação em saúde, privilegiando multidisciplinaridade, economia de custos e gerenciamento tático está em conflito evidente com as idéias de liderança de equipe e autoridade pessoal e inquestionável do cirurgião, embutida no modelo Halstediano e as virtudes de habilidade e resiliência, típicas do cirurgião estereotípico vêm sendo substituídas por novas habilidades ligadas a relações interpessoais e capacitação tecnológica. Do ponto de vista do médico jovem, faz mais sentido um novo modelo de atuação, caracterizado por interatividade, autoridade profissional e capacidade de conformação do que o modelo clássico estereotípico baseado fundamentalmente em autoridade pessoal, reputação, responsabilidade e dominância.

Sim, ainda precisamos de cirurgiões treinados, moralmente confiáveis e disciplinados (sempre precisaremos). Mas há sérias dúvidas quanto à forma de treiná-los.

É possível e necessário substituir a dualidade imposta no dia a dia dos hospitais e dos fóruns de discussão intra-hospitalares, entre sucesso-autoridade versus críticaerros-inadequação-culpa, por debates mais equilibrados, em que a discordância bem fundamentada seja bem vinda e erros/ insucessos sejam exibidos com intenção de aprendizado e crítica não necessariamente punitiva. É fundamental banir dos centros de formação ocasiões em que discussões de casos sejam pretexto para intimidação e demonstração concreta das autoridades hierárquicas, substituídas pelo surgimento de lideranças técnicas e grupais espontâneas aceitas pelo grupo, pela aceitação dos limites individuais e das realizações grupais, em lugar dos sucessos individuais apenas balizados pelos demais integrantes da equipe.

Precisamos de cirurgiões que sejam treinados no sentido da uma aprendizagem real e integrativa / significativa. Gente que vai aprender a aproveitar seus substratos 
de conhecimento para assimilar novos conhecimentos em qualquer tempo e situação. Gente apta a se adaptar e sedimentar novos conceitos (em suma, gente que será capaz de aprimorar e superar sua base de treinamento de forma praticamente imediata), a perceber e escolher o aprendizado de aspectos que estejam de acordo com seus interesses, aptidões e ambientes de trabalho. Profissionais que apliquem uma certa plasticidade cognitiva em tempo real. Cirurgiões que se imponham pela argumentação e pelo conhecimento, não apenas pela tenacidade, memória, coragem, autoridade e espírito de sacrifício pessoal, em que pese a grandeza destas qualidades.

Precisamos, mais do que nunca, transitar de um modelo que prioriza a intensidade de exposição ao paciente e à sala de cirurgia por um novo modelo que priorize a qualificação intelectiva do profissional em formação. O novo cirurgião deverá ser alguém capaz de ANALISAR e não REPETIR cada ato cirúrgico (aprender, ao invés de replicar).

Não menos importantes são os argumentos éticos que discutem o treinamento em serviço dos jovens cirurgiões versus o risco imposto aos pacientes que, inclusive, têm o direito de ser informados e podem escolher se aceitam ou não ser operados por profissionais em treinamento. Simplesmente não é mais aceitável eticamente que a cirurgia/ o paciente seja (apenas) um objeto de treinamento ou, ainda pior, o comportamento freqüente de premiar o residente com a cirurgia ou castigá-lo com a ausência dela. O ato de operar um ser humano só pode ser aceito mediante segurança para o paciente. O treinando não pode receber a autorização para operar sem que tenha a aptidão mínima para a cirurgia em questão, variável individualmente e independente de um padrão temporal, em- bora o ritmo de aprendizagem numa determinada comunidade obedeça a uma curva normal. Portanto, é inaceitável que um residente opere um determinado doente apenas com a argumentação de que ele precisa desta formação (modelo centrado no aprendiz) e tem direito a ela por cumprir as normas disciplinares e se encontrar num determinado momento temporal de sua formação. Nenhum destes argumentos se sustenta se não houver a aptidão individual para o trabalho requerido, no julgamento do preceptor que, é óbvio, não pode ser basear em vieses individuais ou em argumentos de autoridade.

A discussão quanto até que ponto pode ser aceita a curva de aprendizado é extremamente difícil e, até certo ponto, cruel para com os aprendizes. Atualmente, é um grande foco de debate e pesquisa em literatura o desenvolvimento de sistemas virtuais de treinamento que permitam que o exercício real da cirurgia só aconteça depois da superação de algumas etapas da curva de aprendizado nos sistemas virtuais, à semelhança dos sistemas de treinamento para pilotos de aviação.

Chegamos a um momento em que treinar cirurgiões, embora não prescinda, é claro, de treinamento em serviço, passou a depender muito menos de intensidade de exposição e muito mais de qualidade de exposição. Hoje, definitivamente, é mais fundamental operar de forma extremamente adequada, consciente e crítica um " $n$ " menor de pacientes do que de forma mecânica, mediante repetição de padrão, um "n" vultuoso. É mais importante um treinando individualmente equilibrado e responsável intelectivamente pelos seus atos do que um treinando disciplinado, resiliente e dependente de uma relação entre responsabilidade individual, erro / acerto e sucesso / punição.

\section{A B S T R A C T}

This paper proposes to discuss the training methodologies for young surgeons, considering the modern needs, by discussing their expectations and the reality of the surgeons' job market nowadays. Scientific and technological novelties, the huge amount of information imposed daily, managerial interventions and cost issues modified radically the activities of the surgeons, especially if compared to classical conceptions. Recent re-readings of the classical ethical postulates demand a new behavior of the doctors concerning the patients and the society per se. Contemporaneous social culture bring about individual expectations concerning quality of life and professional perspective issues. It becomes necessary to modify the training methods for surgeons to make them adequate to the need of continuous learning and adaptation to new technological instruments. They also should adapt to social interactions with the patients and the other health professionals that fit nowadays expectations. Those structural adaptations are fundamental to maintain the interest of the new professionals in the area of surgery.

Key words: Education, medical. Surgery/education. Professional practice.

\section{REFERENCIAS}

1. Clyde C, Bax T, Merg A, MacFarlane M, Lin P, Beyerdorsf S, McNevin MS. Timing of intervention does not affect outcome in acute appendicitis in a large community practice. Am J Surg. 2008; 195(5):590-2; discussion 592-3.

2. Lavonius NI, Liesjarvi S, Liskaner RO, Ristkari SK, Korkala O, Mokka RE. Simple ligation vs stump inversion in appendicectomy. Ann Chir Gynaecol. 1996; 85(3):222-4.
3. Mason RJ. Surgery for appendicitis: is it necessary? Surg Infect (Larchmt). 2008; 9(4):481-8.

4. Bajammal S, Dahm P, Scarpero HM, Orovan W, Bhandari M. How to use an article about therapy. J Urol. 2008; 180(5):1904-11. Epub 2008 Sep 17.

5. Moreira, MA. Aprendizagem significativa critica. In: Atas do $3^{\circ}$ Encontro Internacional sobre Aprendizagem Significativa, 2000; Lisboa, Portugal. p. 33-5.

6. Friedman P. The arduousness of excellence. Arch Surg. 1998; 133(4):354-60. 
7. Firor WM. Residency training in surgery. Birth, decay, and recovery. Rev Surg. 1965; 22:153-7.

8. Carneiro MB, Gouveia VV, editores. O Médico e seu trabalho. Aspectos metodológicos e resultados no Brasil. $1^{a}$ ed. Brasília: Conselho Federal de Medicina; 2004.

9. Jesus LE. Ensinar cirurgia. Como e para quem? Rev Col Bras Cir. 2008; 35(2):136-40.

10. Dedecca CS, Ribeiro CSMF, Ishii FH. Gênero e jornada de trabalho: análise das relações entre mercado de trabalho e família. Trab Educ Saúde. 2009; 7(1):65-90.
Recebido em 22/01/2009

Aceito para publicação em 10/03/2009

Conflito de interesse: nenhum

Fonte de financiamento: nenhuma

\section{Como citar este artigo:}

Jesus LE. Treinar cirurgiões: hoje como sempre? Rev Col Bras Cir. [periódico na Internet] 2009; 36(6). Disponível em URL: http:// www.scielo.br/rcbc

\section{Endereço para correspondência:}

Lisieux Eyer de Jesus

lisieux@uol.com.br 